\title{
HUBUNGAN KELIMPAHAN FITOPLANKTON, KONSENTRASI KLOROFIL-a DAN KUALITAS PERAIRAN PESISIR SUNGSANG, SUMATERA SELATAN
}

\section{CORRELATION AMONG PHYTOPLANKTON ABUNDANCE, CHLOROPHYLL-a, AND WATER QUALITY OF SUNGSANG COASTAL WATERS, SOUTH SUMATERA}

\author{
Moh. Rasyid Ridho ${ }^{*}$, Enggar Patriono ${ }^{1}$, \& Yenni Sri Mulyani ${ }^{2}$ \\ ${ }^{1}$ Jurusan Biologi, FMIPA-UNSRI, Sumatera Selatan, 30662, Indonesia \\ ${ }^{2}$ Program Studi Manajemen Sumber Daya Perairan, Fakultas Perikanan-UNISKI, \\ Sumatera Selatan, 30611, Indonesia \\ *E-mail: moh.rasyidridho@ mipa.unsri.ac.id
}

\begin{abstract}
Diversity and abundance of fish rely on phytoplankton abundance as food. Meanwhile, an abundance of phytoplankton depends on water quality. In order to understand relationship among those components, this study was carried out to analyzed correlation among phytoplankton abundance chlorophyll-a concentration and water quality. This study was conducted in the coastal waters of sungsang, Banyuasin Regency from July until August 2017. Sample collected using purposive sampling method. Results of the research showed that clarity around 6.3-45.5\%, turbidity 2-4 NTU, temperature 29.6-30.8 $\mathrm{C}^{\circ} \mathrm{pH}$ 6.0-7.7, salinity 0-16 ppt, DO 5.33-6.50 mg/L, BOD 0.4-3.6 mg/L, ammonia 0.1-0.32 mg/L, phosphate 0.01-2.16 mg/L, nitrate 0.06-2.96 mg/L, chlorophyll-a 1.68-20.6 $\mathrm{mg} / \mathrm{m}^{3}$. There was positive correlation among chlorophyll-a and phytoplankton, phosphate, nitrate, $\mathrm{DO}, \mathrm{BOD}_{5}$ about $95.5 \%, 91 \%, 76.6 \%, 82.2 \%,-63 \%$, respectively. The higher the concentration of phosphate and nitrate the higher the concentration of chlorophyll-a, and the higher the concentration of chlorophyll-a causes the higher the concentration of dissolved oxygen. The higher the BOD5 and ammonia, the lower the concentration of chlorophyll-a.
\end{abstract}

Keywords: Banyuasin Regency, chlorophyll-a, Sungsang coastal, water quality

\begin{abstract}
ABSTRAK
Keanekaragaman dan kelimpahan ikan di perairan sangat tergantung dari kelimpahan fitoplankton sebagai makanannya, sedangkan kelimpahan fitoplankton tergantung kondisi kualitas perairan. Sebagai upaya mengetahui hubungan tersebut maka dilakukan penelitian ini yang bertujuan menganalisis hubungan kelimpahan fitoplankton, konsentrasi klorofil-a dan kualitas perairan. Penelitian ini dilakukan di perairan pesisir Sungsang, Sumatera Selatan dari Bulan Juli sampai Agustus 2017. Pengambilan sampel dilakukan dengan metode purposive sampling. Hasil penelitian menunjukkan bahwa kecerahan berkisar antara 6,3-45,5\%, kekeruhan 2-4 NTU, suhu 29,6$30,8^{\circ} \mathrm{C}$, pH 6,0-7,7, salinitas 0-16 ppt, DO 5,33-6,50 mg/L, BOD 0,4-3,6 mg/L, amonia 0,1-0,32 mg/L, fosfat $0,01-216 \mathrm{mg} / \mathrm{L}$, nitrat $0,006-2,96 \mathrm{mg} / \mathrm{L}$, klorofil-a $1,68-20,6 \mathrm{mg} / \mathrm{m}^{3}$ kelimpahan fitoplankton berkisar (96-240) $\mathrm{mg} / \mathrm{L}$. Terdapat hubungan positif antara konsentrasi klorofil-a dengan fitoplankton, fosfat, nitrat, $\mathrm{DO}, \mathrm{BOD}_{5}$, secara berturut-turut sebesar 95,5\%, 91\%, 76,6\%, 82,2\%, -63\%. Semakin tinggi konsentrasi fosfat dan nitrat makin tinggi pula konsentrasi klorofil-a, dan semakin tinggi konsentrasi klorofil-a menyebabkan konsentrasi oksigen terlarut semakin tinggi. Semakin tinggi $\mathrm{BOD}_{5}$ dan amonia maka konsentrasi klorofil-a makin rendah.
\end{abstract}

Kata kunci: Kabupaten Banyuasin, klorofil-a, kualitas perairan, Pesisir Sungsang 


\section{PENDAHULUAN}

Perairan Pesisir Sungsang, Sumatera Selatan merupakan muara Sungai Musi yang potensial untuk produksi perikanan tangkap. Muara sungai atau biasa disebut dengan estuari merupakan perairan semi tertutup yang berhubungan bebas dengan laut, sehingga air laut dengan salinitas tinggi dapat bercampur dengan air tawar (Prianto et al., 2017). Perairan estuari adalah sebagai tujuan akhir dari suatu aliran sungai. Di daerah estuari ini kondisi perairannya dinamis, karena menerima beban dari daratan dan debit air sungai. Pada daerah ini akan terjadi proses fisika seperti sedimentasi dan kimia karena percampuran air tawar dengan air laut. Sepanjang aliran Sungai Musi banyak terdapat pabrik seperti pabrik pupuk, minyak, galangan kapal dan lain-lain. Sepanjang aliran Sungai Musi merupakan hunian masyarakat, dan juga terdapat pasar. Aktivitas-aktivitas tersebut menghasilkan buangan, baik organik maupun anorganik. Apabila proses pembilasan buangan bahan organik dan anorganik oleh aliran sungai ke estuaria tidak berlangsung dengan sempurna, maka proses degradasi tidak dapat berjalan dengan sempurna. Sehingga, bahan-bahan organik dan anorganik akan menjadi beban di muara sebagai pencemar. Sebaliknya, jika pembilasan oleh air sungai berlangsung dengan sempurna maka proses degradasi juga akan berjalan dengan sempurna, sehingga bahan organik dan anorganik yang terbawa aliran sungai akan menjadikan estuari sebagai perairan yang subur. Indikator perairan dalam kondisi subur dapat ditunjukkan oleh kandungan klorofil-a. Klorofil-a merupakan salah satu parameter yang sangat menentukan produktivitas primer di perairan. Sebaran dan konsetrasi klorofil-a sangat terkait dengan keberadan fitoplankton. Fitoplankton merupakan makanan larva pada fase postlarvae. Keanekaragaman dan kelimpahan larva ikan di perairan sangat tergantung dari kelimpahan fitoplankton sebagai makanannya, dan kelimpahan fitoplankton tergantung kondisi kualitas perairan. Beberapa paramater fisika-kimia yang mengontrol dan mempengaruhi sebaran klorofil-a adalah suhu, cahaya dan arus. Oleh karena itu penelitian ini dilakukan dengan tujuan untuk menganalisis hubungan kelimpahan fitoplankton, konsentrasi klorofil-a dan kualitas perairan Sungsang, pesisir Sumatera Selatan.

\section{METODE PENELITIAN}

\subsection{Waktu dan Tempat}

Penelitian dilaksanakan di perairan sekitar pesisir Sungsang, Kabupaten Banyuasin (Figure 1). Sampel diambil pada bulan Juli-Agustus 2017 dan pengamatan fitoplankton dilakukan di Laboratorium Jurusan Biologi FMIPA, Universitas Sriwijaya. Analisis kandungan klorofil-a dilakukan di laboratorium PT. Sucofindo, Cabang Palembang.

\subsection{Pengambilan Sampel dan Pengukuran Parameter Kualitas Perairan}

Penentuan lokasi sampling dilakukan secara purposive berdasarkan keterwakilan lokasi perairan dari arah aliran Sungai Telang, Sungai Musi dan air laut. Pengambilan sampel air untuk klorofil-a dilakukan di permukaan perairan secara in situ, kemudian dianalisis kandungan klorofilnya dengan metode Parson et al. (1984). Metode pengukuran kualitas air disajikan pada Table 1 .

Sampel plankton diambil dengan menyaring air sebanyak $50 \mathrm{~L}$ dari lokasi sampling menggunakan plankton net berukuran $30 \mu \mathrm{m}$, ember ukuran $5 \mathrm{~L}$ dan dilakukan sebanyak 10 kali penyaringan. Sampel yang tertampung diawetkan dengan formalin dan diberi label. Sampel tersebut diidentifikasi menggunakan mikroskop pembesaran 10x10 atau 10x40. Identifikasi jenis plankton dilakukan dengan merujuk pada buku "Pedoman Identifikasi Plankton" (Yamaji, 1966; Davis, 1955; Mizuno, 1979). 

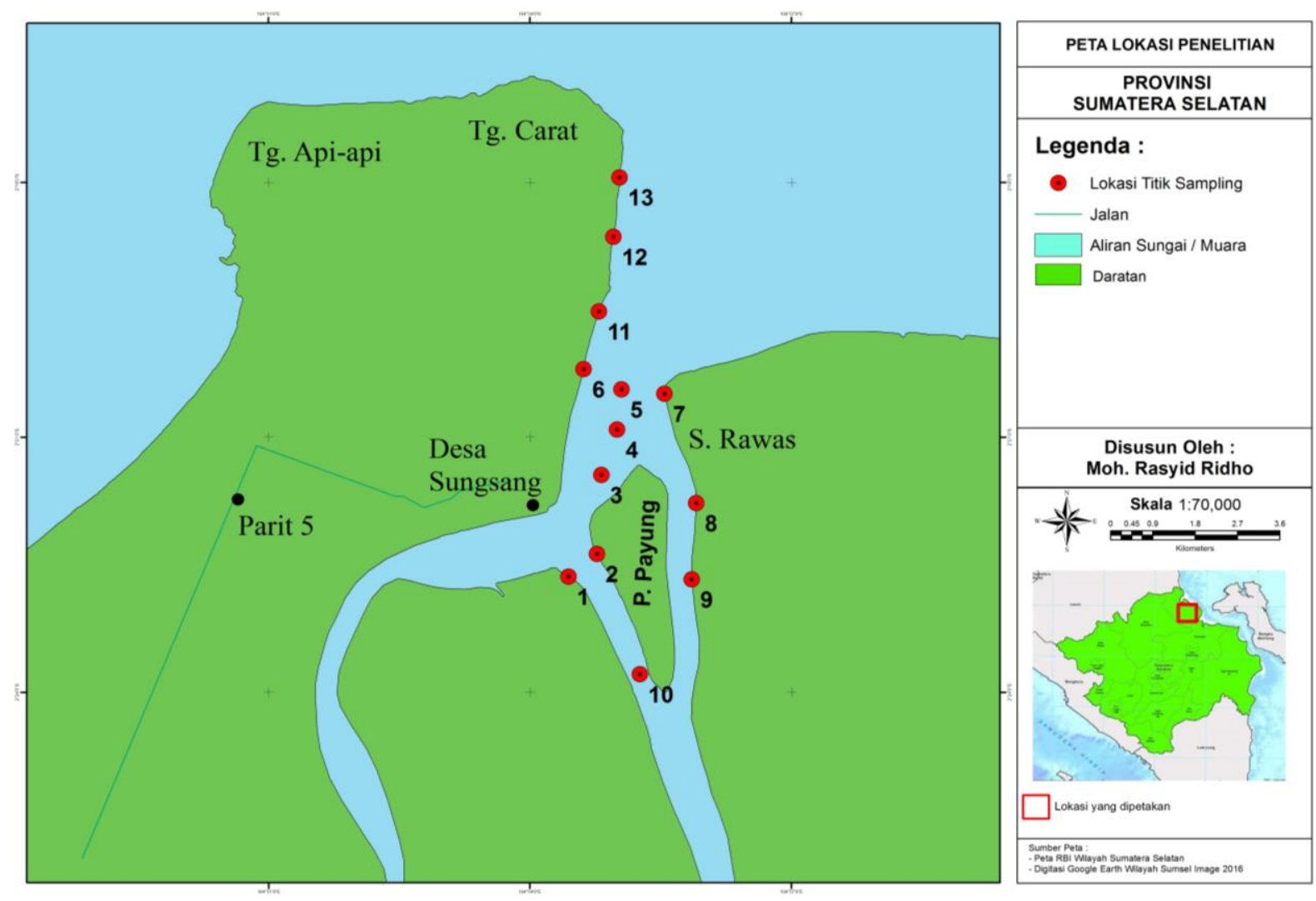

Figure 1. Study location in coastal waters of Sungsang.

Table 1. Method of water quality measurement.

\begin{tabular}{|c|c|c|c|}
\hline No. & Parameter & Unit & Methods/tools \\
\hline 1. & Brightness & $\%$ & In-situ/secchi disk \\
\hline 2. & Turbidity & NTU & turbidimeter \\
\hline 3. & Temperature & ${ }^{\circ} \mathrm{C}$ & In-situ/termometer \\
\hline 4. & $p H$ & & *) $4500-\mathrm{H}^{+}-\mathrm{B} / \mathrm{pH}$ meters \\
\hline 5. & Salinity & $\%$ & In-situ/refractometer \\
\hline 6. & $D O$ & $\mathrm{mg} / \mathrm{L}$ & *) $4500-\mathrm{O}-\mathrm{B} / \mathrm{DO}$ meters \\
\hline 7. & $B O D$ & $\mathrm{mg} / \mathrm{L}$ & *) $5210 \mathrm{~B}$ \\
\hline 8. & Ammonia & $\mathrm{mg} / \mathrm{L}$ & *) $4500-\mathrm{NH}_{3}-\mathrm{F}$ \\
\hline 9. & Phosphate & $\mathrm{mg} / \mathrm{L}$ & *) 4500-P-C \\
\hline 10. & Nitrate & $\mathrm{mg} / \mathrm{L}$ & *) $4500-\mathrm{NO}_{3}-\mathrm{B}$ \\
\hline & Chlorophyll-a & $\mathrm{mg} / \mathrm{m}^{3}$ & Spectrophotometry \\
\hline
\end{tabular}

*) Standard methods for water and wastewater observation, 22nd Edition.

\subsection{Analisis Hubungan antara}

Konsentrasi Klorofil-a dengan

Kelimpahan Fitoplankton

Hubungan konsentrasi klorofil-a dengan parameter perairan dianalisis menggunakan Principal Component Analysis (PCA) (Johnson \& Wichern, 1992).

\section{HASIL DAN PEMBAHASAN}

\subsection{Konsentrasi Klorofil-a di Muara Sungai Musi}

Hasil penelitian menunjukkan nilai konsentrasi klorofil-a di perairan sekitar 
Sungsang, pesisir Kabupaten Banyuasin, disajikan pada Table 2.

Table 2. Consentration of chlorophyll-a in the Sungsang waters.

\begin{tabular}{cc}
\hline Site & Chlorophyll- $a\left(\mathrm{mg} / \mathrm{m}^{3}\right)$ \\
\hline 1 & 10.12 \\
2 & 7.65 \\
3 & 5.89 \\
4 & 9.2 \\
5 & 15.35 \\
6 & 9.44 \\
7 & 15.98 \\
8 & 7.32 \\
9 & 6.57 \\
10 & 20.6 \\
11 & 12.31 \\
12 & 6.91 \\
13 & 10.12 \\
\hline
\end{tabular}

Konsentrasi klorofil-a di perairan sekitar Sungsang berkisar antara $(0,48-19,4)$ $\mathrm{mg} / \mathrm{m}^{3}$. Konsentrasi klorofil-a adalah salah satu komponen penting dalam proses fotosintesis oleh fitoplankton dan dapat digunakan sebagai indikator utama untuk mengestimasi produktivitas primer perairan (Chen, 2017). Mikroalga fotosintetik seperti fitoplankton merupakan penyumbang produktifitas primer utama di perairan (Iriate \& Purdie, 1994; Chen, 2017). Sebagai produsen primer, organisme ini mampu mengubah bahan anorganik menjadi bahan organik melalui fotosintesis. Oleh karenanya, kandungan klorofil-a digunakan sebagai standing stock fitoplankton yang dapat dijadikan sebagai petunjuk produktivitas primer suatu perairan.

\subsection{Parameter Fisika dan Kimia di Perairan Pesisir Sungsang}

Hasil penelitian yang dilakukan diperoleh parameter fisika dan kimia (Table 4). Suhu perairan berkisar antara $29,6^{\circ} \mathrm{C}$ sampai $30,8^{\circ} \mathrm{C}$. Kisaran suhu optimum bagi pertumbuhan plankton di perairan berkisar antara $20^{\circ} \mathrm{C}-30^{\circ} \mathrm{C}$ (Effendi, 2003). Hal ini tidak akan berpengaruh banyak terhadap kehidupan plankton, karena yang berpengaruh terhadap meningkatnya konsumsi oksigen oleh organisme akuatik sebanyak 23 kali lipat adalah apabila terjadi peningkatan suhu sebesar $10^{\circ} \mathrm{C}$ (Effendi, 2003).

Table 3. Phytoplankton abundance in each study stations.

\begin{tabular}{ccccc}
\hline \multirow{2}{*}{ Site } & \multicolumn{3}{c}{ Class (ind/L) } & $\begin{array}{c}\text { Number of clans } \\
\text { per site }\end{array}$ \\
\cline { 2 - 5 } & Bacillariophyceae & Cyanophyceae & Dinophyceae & 160 \\
\hline 1 & 96 & 32 & 32 & 128 \\
3 & 112 & 16 & 0 & 112 \\
4 & 80 & 16 & 16 & 144 \\
5 & 112 & 32 & 0 & 192 \\
6 & 160 & 16 & 16 & 160 \\
7 & 128 & 32 & 0 & 240 \\
8 & 208 & 16 & 16 & 128 \\
9 & 96 & 23 & 0 & 142 \\
10 & 96 & 46 & 0 & 240 \\
11 & 208 & 16 & 16 & 160 \\
12 & 128 & 16 & 0 & 128 \\
13 & 96 & 32 & 0 & 96 \\
\hline
\end{tabular}


Table 4. Physical and chemical parameters of water in Sungsang waters.

\begin{tabular}{|c|c|c|c|c|c|c|c|c|c|c|c|c|}
\hline St. & $\begin{array}{c}\text { Brigh } \\
\text { thess } \\
(\%)\end{array}$ & $\begin{array}{c}\text { Dept } \\
h \\
(m)\end{array}$ & $\begin{array}{c}\text { Turbi } \\
\text { dity } \\
\text { (NTU) }\end{array}$ & $\begin{array}{c}\text { Temp } \\
\text { eratu } \\
\text { re } \\
\left({ }^{\circ} \mathrm{C}\right)\end{array}$ & $p H$ & $\begin{array}{l}\text { Sali } \\
\text { nity } \\
(\%)\end{array}$ & $\begin{array}{c}D O \\
(m g / L)\end{array}$ & $\begin{array}{c}B O D_{5} \\
(m g / L)\end{array}$ & $\begin{array}{c}\text { Ammonia } \\
\left(\mathrm{NH}_{3}-\mathrm{N}\right)\end{array}$ & $\begin{array}{l}\text { Phos } \\
\text { phate } \\
\left(P_{4}-\right. \\
P)\end{array}$ & $\begin{array}{c}\text { Nitrat } \\
e \\
\left(\mathrm{NO}_{3-}\right. \\
N)\end{array}$ & $\begin{array}{l}\text { Chloro } \\
\text { phyll-a }\end{array}$ \\
\hline 1 & 44.8 & 1.1 & 2 & 30.5 & 7.6 & 10 & 6 & 1 & 0.14 & 1.02 & 2.12 & 10.12 \\
\hline 2 & 45.5 & 1.0 & 2 & 30.8 & 7.7 & 10 & 5.76 & 1.2 & 0.14 & 0.12 & 1.1 & 7.65 \\
\hline 3 & 16.3 & 2.5 & 3 & 30.4 & 6.6 & 5 & 5.76 & 1.2 & 0.14 & 0.01 & 0.08 & 5.89 \\
\hline 4 & 7.7 & 4.8 & 4 & 30.8 & 6.8 & 4 & 5.96 & 0.6 & 0.1 & 1.16 & 2.03 & 9.2 \\
\hline 5 & 6.3 & 5.4 & 4 & 30.2 & 7.1 & 1 & 6.28 & 0.4 & 0.12 & 2.08 & 2.26 & 15.35 \\
\hline 6 & 7.2 & 2.3 & 4 & 30.2 & 6.4 & 2 & 5.41 & 3.6 & 0.32 & 1.04 & 2.12 & 9.44 \\
\hline 7 & 8.1 & 2.2 & 4 & 30 & 6.0 & 0 & 6.2 & 0.5 & 0.1 & 2.16 & 3.05 & 15.98 \\
\hline 8 & 6.7 & 1.8 & 4 & 30.8 & 6.6 & 4 & 5.51 & 2.2 & 0.12 & 0.15 & 1.01 & 7.32 \\
\hline 9 & 30.7 & 1.1 & 4 & 30.8 & 7.5 & 15 & 5.40 & 2.2 & 0.12 & 0.01 & 0.08 & 6.57 \\
\hline 10 & 32 & 1.1 & 2 & 30.2 & 7.4 & 15 & 6.50 & 0.4 & 0.1 & 2.14 & 2.96 & 20.6 \\
\hline 11 & 29.8 & 1.2 & 4 & 30.5 & 7.2 & 14 & 5.48 & 2.8 & 0.1 & 1.8 & 2.21 & 12.31 \\
\hline 12 & 30.8 & 1.3 & 4 & 30.2 & 7.4 & 16 & 5.41 & 2.8 & 0.12 & 0.01 & 0.06 & 6.91 \\
\hline 13 & 27.2 & 1.5 & 4 & 29.6 & 7.4 & 15 & 5.33 & 2.4 & 0.1 & 0.01 & 1.1 & 1.68 \\
\hline
\end{tabular}

Nontji (2002) menyatakan bahwa setiap organisme laut mempunyai toleransi yang besar terhadap perubahan suhu (euriterm), sebaliknya ada pula yang toleransinya kecil (stenoterm). Nybakken (1988) menjelaskan suhu air di estuaria lebih bervariasi daripada di perairan pantai. Hal ini sebagian karena di estuaria volume air lebih kecil sedangkan luas permukaan lebih besar, dengan demikian perairan estuaria ini lebih cepat panas dan lebih cepat dingin. Alasan lain terjadi variasi ini adalah masukan air tawar.

Kecerahan merupakan faktor yang sangat penting dan erat kaitannya dengan produktivitas primer di perairan. Kecerahan berkisar 6,3\%-44,8\% (Table 3). Pada saat dilakukan pengukuran, perairan tersebut tampak keruh dan berwarna coklat. Kondisi ini terjadi karena pada saat melakukan pengambilan sampel perairannya dangkal dan bersubstrat lumpur. Romimohtarto \& Thayib (1982) menyatakan air laut yang keruh nilai kecerahannya dipengaruhi oleh kandungan lumpur, kandungan plankton dan zat-zat terlarut lainnya. Bila kekeruhan itu tinggi dan konsentrasi klorofil juga tinggi, itu berarti bahwa kekeruhan disebabkan oleh adanya fitoplankton.
Nilai salinitas ke-13 lokasi antara 0$16 \%$ dan tergolong mesohalin. Supriharyono (2000) menyatakan bahwa perairan estuari (muara) umumnya memiliki salinitas sangat bervariatif dan cenderung rendah saat surut karena mendapatkan pengaruh aliran air tawar dan cenderung tinggi pada saat pasang karena mendapatkan pengaruh aliran air laut.

Nilai pH (derajat keasaman) di perairan muara Sungai Musi berkisar antara 6,0-7,7. Hal itu sesuai dengan karakter muara yang secara periodik menerima pengaruh dari air tawar yang $\mathrm{pH}$-nya rendah.

Konsentrasi oksigen terlarut di semua lokasi berkisar 5,33-6,5 $\mathrm{mg} / \mathrm{L}$. Hasil penelitian Takarina et al., (2017) menunjukkan bahwa penurunan oksigen secara signifikan mengurangi populasi fitoplankton. Konsentrasi $\mathrm{BOD}_{5}$ di semua lokasi berkisar 14,4-18,6 mg/L. BOD kurang dari $20 \mathrm{mg} / \mathrm{L}$ menunjukkan bahwa konsentrasi oksigen terlarut di perairan pada kondisi yang cukup untuk proses degradaasi bahan organik.

\subsection{Hubungan Fitoplankton, Klorofil-a dan Sifat Fisika Kimia Perairan}

Hasil analisis PCA menunjukkan bahwa dengan dua sumbu sudah dapat 
menerangkan sebesar $93,85 \%$ atau lebih dari $70 \%$ sebagaimana dipersyaratkan dalam penggunaan PCA, dimana sumbu satu memberikan kontribusi sebesar $84,89 \%$ dan sumbu dua memberikan kontribusi sebesar 9,96\% (Table 5 dan Table 6). Sebaran variabel-variabel pengamatan dalam 4 kuadran, sebagai representasi yang menunjukkan pengaruh antara variabel (Figure 2).

Hasil analisis PCA (Table 5) menunjukkan bahwa klorofil-a berkorelasi kuat terhadap fosfat $(90,99 \%)$ dan nitrat $(79,62 \%)$ yang berarti bahwa semakin besar nilai fosfat dan nitrat, nilai klorofil juga semakin tinggi. Hal itu karena fitoplankton akan memanfaatkan fosfat dan nitrat sebagai nutrien untuk reproduksinya. Semakin banyak fitoplankton, dan aktivitas fitoplankton adalah melakukan fotosintesis. Proses fotosintesis akan menghasilkan oksigen, sehingga kadar oksigen terlarut juga makin tinggi, dimana ditunjukkan oleh nilai klorofil-a sebesar $82,21 \%$. Sedangkan BOD dan amonia akan memberikan pengaruh negatif terhadap klorofil-a, hal itu ditunjukkan dengan nilai korelasi negatif.

\section{Table 5. Component 2: Variance on} component 1 and 2.

\begin{tabular}{ccc}
\hline$P C$ & Eigenvalue & \% variance \\
\hline 1 & 2008.06 & 89.18 \\
2 & 226.57 & 10.06 \\
3 & 13.18 & 0.59 \\
4 & 2.37 & 0.11 \\
5 & 0.76 & 0.03 \\
6 & 0.42 & 0.02 \\
7 & 0.19 & 0.01 \\
8 & 0.08 & 0.00 \\
9 & 0.04 & 0.00 \\
10 & 0.01 & 0.00 \\
\hline
\end{tabular}

Sebaran klorofil-a di perairan sangat tergantung kualitas perairan terutama konsentrasi nutrien. Daerah pesisir memiliki tingkat prodiktivitas primer yang lebih tinggi jika dibandingkan dengan perairan lain karena daerah ini merupakan daerah transisi daratan ke lautan sehingga memiliki sediaan bahan organik yang tinggi (Cloern et al., 2014). Lebih lanjut, diungkapkan oleh penelitian Irawati et al., (2013) di perairan teluk Kendari bahwa nutien berupa nitrat dan cahaya matahari memberikan pengaruh nyata terhadap produktivitas primer perairan.

Table 6. Component 1: contribution of waters quality to main component 1 and 2.

\begin{tabular}{lrrr}
\hline \multicolumn{1}{c}{0} & \multicolumn{1}{c}{ Axis 1 } & \multicolumn{1}{c}{ Axis 2 } & \multicolumn{1}{c}{ Axis 3 } \\
\hline$(\%)$ & -0.13 & 0.4989 & 0.139 \\
$(\mathrm{NTU})$ & -0.09 & -0.4304 & 0.2298 \\
$\left({ }^{\circ} \mathrm{C}\right)$ & -0.08 & 0.09315 & -0.7009 \\
$\mathrm{pH}$ & -0.16 & 0.4798 & 0.1259 \\
$(\% \circ)$ & -0.1989 & 0.397 & 0.3962 \\
$\mathrm{DO}$ & 0.3956 & 0.1635 & -0.1896 \\
$\mathrm{BOD}$ & -0.3216 & -0.2419 & 0.3192 \\
$\left(\mathrm{NH}_{3}-\mathrm{N}\right)$ & -0.0598 & -0.2729 & 0.06411 \\
$\left(\mathrm{PO}_{4}-\mathrm{P}\right)$ & 0.4054 & -0.02268 & 0.2147 \\
$\left(\mathrm{NO}_{3}-\mathrm{N}\right)$ & 0.3836 & -0.02143 & 0.2125 \\
Chl-a & 0.4071 & 0.08646 & 0.08365 \\
Phyto & 0.4062 & 0.03292 & 0.1534 \\
\hline
\end{tabular}

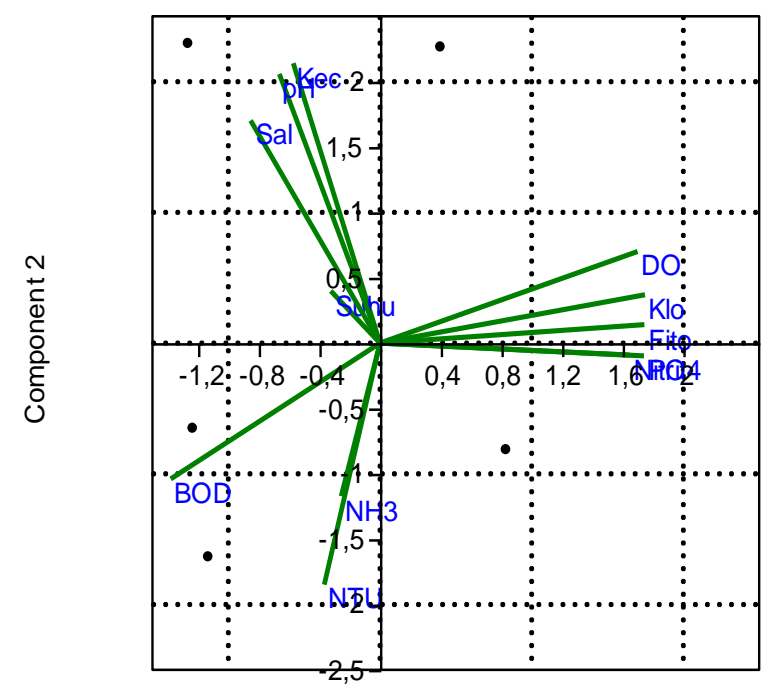

Component 1

Figure 2. Representation of first axis (89.19\%) and second axis $(10.06 \%)$. 
Table 7. Correlation value among parameters.

\begin{tabular}{llllllllllll}
\hline & $\begin{array}{l}\text { Bright } \\
\text { ness }\end{array}$ & $\begin{array}{l}\text { Turbi } \\
\text { dity }\end{array}$ & $\begin{array}{l}\text { Tempe } \\
\text { rature }\end{array}$ & $p H$ & Salinity & DO & BOD 5 & $\begin{array}{l}\text { Ammo } \\
\text { nia }\end{array}$ & $\begin{array}{l}\text { Phos } \\
\text { phate }\end{array}$ & $\begin{array}{l}\text { Nitr } \\
\text { ate }\end{array}$ & Chl-a \\
\hline Turbidity & -0.673 & 0 & & & & & & & & & \\
Temperature & 0.124 & -0.183 & 0 & & & & & & & & \\
pH & 0.848 & -0.474 & 0.152 & 0 & & & & & & & \\
Salinity & 0.773 & -0.239 & -0.056 & 0.791 & 0 & & & & & & \\
DO & -0.088 & -0.464 & -0.064 & -0.095 & -0.328 & 0 & & & & & \\
BOD & -0.017 & 0.515 & -0.035 & -0.033 & 0.199 & -0.935 & 0 & & & & \\
Ammonia & -0.208 & 0.042 & -0.037 & -0.289 & -0.334 & -0.293 & 0.501 & 0 & & & \\
Phosphate & -0.265 & -0.028 & -0.223 & -0.277 & -0.326 & 0.730 & -0.506 & -0.092 & 0 & & \\
Nitrate & -0.203 & -0.142 & -0.248 & -0.279 & -0.353 & 0.673 & -0.466 & 0.020 & 0.916 & 0 & \\
Chlorophyll-a & -0.127 & -0.249 & -0.076 & -0.168 & -0.215 & 0.822 & -0.626 & -0.119 & 0.910 & 0.796 & 0 \\
Phytoplankton & -0.170 & -0.160 & -0.188 & -0.274 & -0.258 & 0.780 & -0.586 & -0.083 & 0.887 & 0.808 & 0.955 \\
\hline
\end{tabular}

\section{KESIMPULAN}

Berdasarkan hasil yang diperoleh dapat disimpulkan bahwa, kandungan klorofil-a di perairan pesisir Sungsang berkisar antara 0,48-19,4 $\mathrm{mg} / \mathrm{m}^{3}$. Semakin tinggi konsentrasi fosfat dan nitrat semakin tinggi konsentrasi klorofil-a, dan semakin tinggi konsentrasi klorofil-a menyebabkan konsentrasi oksigen terlarut semakin tinggi. Semakin tinggi BOD $_{5}$ dan amonia konsentrasi klorofil-a makin rendah.

\section{UCAPAN TERIMA KASIH}

Terima kasih kepada Fakultas Matematika dan Ilmu Pengetahuan Alam Universitas Sriwijaya dan Fakultas Perikanan Universitas Islam OKI, Kayuagung atas dukungan terhadap penelitian ini

\section{DAFTAR PUSTAKA}

Chen, H., W. Zhoua, W. Chena, W. Xie, L. Jiang, Q. Liang, M. Huang, Z. Wub, \& Q. Wang. 2017. Simplified, rapid, and inexpensive estimation of water primary productivity based on chlorophyll fluorescence parameter Fo. J. of Plant Physiology, 211: 128135. http://doi.org/10.1016/j.jplph.2016.12 .015
Cloern, J.E., S.Q. Foster, \& A.E. Kleckner. 2014. Phytoplankton primary production in the world's estuarinecoastal ecosystems. Biogeosciences, 11: 2477-2501. http://doi.org/10.5194/bg-11-24772014

Davis, C.C. 1995. The marine and freshwater plankton. Michigan State University Press. United States of America. 562 p.

Effendi, H. 2003. Telaah kualitas air: bagi pengelolaan sumberdaya dan lingkungan perairan. Penerbit Karsinus. Yogyakarta. 257 p.

Irawati, N., E.M. Adiwilaga, \& N.T.M. Prawtiwi. 2013. Hubungan produktivitas primer fitoplankton dengan ketersediaan unsur hara dan intensitas cahaya di perairan Teluk Kendari Sulawesi Tenggara. J. Biologi Tropis, 13(2): 197-208. http://doi.org/10.29303/jbt.v13i2.152

Iriate, A. \& D.A. Purdie. 1994. Size distribution of chlorophyll-a biomass and primary production in a temperate estuary (Southampton Water): the contribution of photosynthetic picoplankton. Marine EcologyProgress Series, 115: 283-297. http://doi.org/10.3354/meps 115283

Johnson, R.A. \& D.W. Wichern. 1992. Applied multivariate statistical 
analysis. Prentice hall: New Jersey. Amerika Serikat. 773 p.

Mizuno. 1979. Illustration of the fresh-water plankton of Japan. Haikusha Publishing co ltd. Osaka, Japan. 353 p.

Nontji, A. 2002. Laut Nusantara. Penerbit Djambatan. Jakarta. 331 p.

Nybakken, J.W. 1988. Biologi laut suatu pendekatan ekologis. Penerjemah Muhammad Eidman, Koesoebiono, Dietriech Geoffrey Bengen, Malikkusworo Hutomo dan Sukristijono Sukardjo. PT Gramedia Pustaka Utama. Jakarta. 459 p.

Prianto, E., S. Kaban, S. Aprianti, \& R. Jhonnerie. 2017. Pengendalian sumberdaya ikan di estuaria Sungai Musi. J. Kebijakan Perikanan Indonesia, 2(1): 15-25. http://doi.org/10.15578/jkpi.2.1.2010. $15-25$

Romimohtarto, K. \& S. Thayib. 1982. Kondisi lingkungan pesisir dan laut di
Indonesia. Lembaga Oseanologi Nasional LIPI. Jakarta. 246 p.

Supriharyono. 2000. Pelestarian dan pengelolaan sumber daya alam di wilayah pesisir tropis. PT Gramedia Pustaka Utama. Jakarta. 246 p.

Takarina, N.D., W. Wardhana, \& T. Soedijarti. 2017. Impact of oxygen depletion on planktonic community with emphasis temperature dynamics at aquaculture scale in Blanakan, West Java. Proceeding The 3rd International Seminar on Mathematics, Science, and Computer Science Education, Bandung, Indonesia. 15 Oktober 2016. 1-6 pp. http://doi.org/10.1063/1.4983932

Yamaji, I. 1966. Illustrations of The Marine Plankton of Japan. Hoikusha Publishing Co. Japan. 192 p.

Received :09 April 2019

Reviewed : 20 June 2019

Accepted : 25 January 2020 